\title{
Significance Level
}

National Cancer Institute

\section{Source}

National Cancer Institute. Significance Level, NCI Thesaurus. Code C41265.

The probability of a type I error of a statistical hypothesis test, a fixed probability of wrongly rejecting the null hypothesis $\mathrm{HO}$, if it is in fact true. It is set by the investigator in relation to the consequences of such an error. The often chosen significance level is $5 \%$. 